\title{
EDUCAÇÃO A DISTÂNCIA NO ENSINO SUPERIOR: uma possibilidade concreta de inclusão social
}

\section{Distance education at the superior teaching: a concrete possibility of social inclusion ${ }^{l}$}

\author{
Maria Cristina Lima Paniago Lopes ${ }^{[a]}$, Blanca Martín Salvago ${ }^{[b]}$, \\ Jeferson Pistori ${ }^{[c]}$, Arlinda Cantero Dorsa ${ }^{[d]}$, \\ Déa Terezinha Rímoli de Almeida ${ }^{[e]}$ \\ [a] Professora Doutora do Mestrado em Educação na Universidade Católica Dom Bosco \\ (UCDB), Campo Grande, MS - Brasil, e-mail: cristinapaniago@acad.ucdb.br \\ [b] Coordenadora Pedagógica da EAD - (UCDB), Campo Grande, MS - Brasil, e-mail: \\ blanca@ucdb.br \\ [c] Professor Doutor e Diretor da EAD - (UCDB), Campo Grande, MS - Brasil, e-mail: \\ jpistori@ucdb.br \\ [d]Professora Doutora na EAD - (UCDB), Campo Grande, MS - Brasil, e-mail: \\ arlindadorsa@ucdb.br \\ [e] Universidade Católica Dom Bosco (UCDB), Campo Grande, MS - Brasil, e-mail: \\ dea@ucdb.br
}

Esta pesquisa faz parte dos trabalhos desenvolvidos pelo GETED (Grupo de Pesquisa e Estudos em Tecnologia Educacional e Educação a Distância da UCDB) e foi apresentada no XII Seminário Nacional Universitas/BR com publicação do texto completo nos anais.

Rev. Diálogo Educ., Curitiba, v. 10, n. 29, p. 191-204, jan./abr. 2010 


\title{
Resumo
}

Neste artigo discutimos a inclusão social e a educação superior a distância. Para isso, partimos de algumas definições de Educação a Distância (EAD); em seguida, traçamos um breve histórico da EAD, suas bases legais no Brasil e seus indicadores de qualidade; por fim, apresentamos alguns modelos usados no Ensino Superior a Distância, destacando como uma instituição universitária particular, que oferece cursos de graduação a distância, contribui para a inclusão social. Concluímos que, no início, a Educação a Distância era vista como algo totalmente desvinculado da educação presencial. Porém, hoje, estamos assistindo a uma aproximação no sentido de uma contribuição mútua. Ao invés de ser vista como uma rival, a EAD traz novas possibilidades de comunicação e informação, além de fazer com que repensemos nossas práticas. Portanto, as duas modalidades podem conviver em harmonia, aproveitando o que de melhor cada uma oferece.

Palavras-chave: Ensino superior a distância. Inclusão social. Indicadores de qualidade.

\begin{abstract}
At this article we discuss the social inclusion and the Distance Superior Education. To do that, we start with some Distance Education definitions; then, we show a brief description of the Distance Education, its legal bases in Brazil and its indicators of quality; at least, we present some models used at the Distance Superior Education, emphasizing how a private University Institution which offers Distance Graduation Courses contributes to the social inclusion.
\end{abstract}

Keywords: Distance high education. Social inclusion. Indicators of quality.

Rev. Diálogo Educ., Curitiba, v. 10, n. 29, p. 191-204, jan./abr. 2010 


\section{INTRODUÇÃO}

Popularmente, o termo Educação a Distância vem sendo relacionado à Inclusão Digital, principalmente pelo avanço e uso das tecnologias nos modelos de EAD, ao invés de colocar a problemática em um contexto mais amplo, que é a possibilidade que esta metodologia de ensino oferece para a Inclusão Social.

É certo que a sociedade pode ser beneficiada com a EAD na promoção da Inclusão Digital, porém, ela é uma ferramenta que tem um alcance ainda maior, principalmente para suprir as necessidades da população que não tem acesso ao ensino superior tradicional, seja por motivos geográficos ou indisponibilidade flexível de tempo, muitas vezes tendo que conciliar suas várias atividades para sobreviver, prejudicando a possibilidade de adquirir novos conhecimentos.

A EAD no Brasil teve impulso por causa do artigo 80 da LDB que dispõem que: "O Poder Público incentivará o desenvolvimento e a veiculação de programas de ensino a distância, em todos os níveis e modalidades de ensino, e de educação continuada.", neste momento, a EAD passa a ser incluída nas políticas públicas de ensino.

A Educação a Distância é colocada como um veículo importante para inclusão social, e a LDB determina um tratamento diferenciado, que inclui:

a) I - custos de transmissão reduzidos em canais comerciais de radiodifusão sonora e de sons e imagens;

b) II - concessão de canais com finalidades exclusivamente educativas;

c) III - reserva de tempo mínimo, sem ônus para o Poder Público, pelos concessionários de canais comerciais.

No ensino superior, a Educação a Distância teve início com o oferecimento de cursos de formação de professores, principalmente para atender o disposto no artigo $87 \int 4^{\circ}$ da LDB, que estabelece que até o final de 2006, somente serão admitidos professores habilitados em nível superior ou formados por treinamento em serviço nas escolas.

A partir dessas experiências iniciais, a Educação a Distância passou a ser utilizada também para atender outras demandas da sociedade, e hoje em dia tem como foco atender alunos com dificuldade de acesso ao Ensino Superior.

Rev. Diálogo Educ., Curitiba, v. 10, n. 29, p. 191-204, jan./abr. 2010 


\section{Definições de Educação a Distância}

Há algumas definições de EAD que enfatizam a separação espacial e temporal. Perry e Rumble (1987, p. 1-2) afirmam que na EAD, professor ou tutor e aluno não se encontram juntos no mesmo espaço físico, e por isso, necessitam de meios que possibilitem uma comunicação entre ambos.

Essa separação física também é evidenciada por Moran (1994, p. 1), quando define Educação a Distância como um "processo de ensino-aprendizagem, mediado por tecnologias, onde professores e alunos estão separados espacial e/ou temporalmente". Para esse autor, EAD é o "ensino/aprendizagem onde professores e alunos não estão normalmente juntos, fisicamente, mas podem estar conectados, interligados por tecnologias, principalmente as telemáticas, como a Internet". Moran lembra que outras tecnologias também podem ser utilizadas, como o correio, o rádio, a televisão, o vídeo, o CD-ROM, o telefone, o fax.

Indo ao encontro dessa característica de separação física, B. Holmberg (1985) pontua a importância de se ter um planejamento na organização do ensino pela supervisão não imediata de tutores presentes com seus alunos no mesmo local.

Além da separação física, há outra característica que aparece nas definições de EAD, algo não pronto, acabado: "a EAD não é um fast-food em que o aluno se serve de algo pronto" (MORAN, 1994, p. 3). Para o autor, a EAD é "uma prática que permite um equilíbrio entre as necessidades e habilidades individuais e as do grupo - de forma presencial e virtual. Nessa perspectiva, é possível avançar rapidamente, trocar experiências, esclarecer dúvidas e inferir resultados".

Por outro lado, Belloni (1999, p. 3) pontua a questão do deslumbramento em utilizar a tecnologia de modo indiscriminado, "mais por suas virtualidades técnicas do que por suas virtudes pedagógicas". Por isso, "se é fundamental reconhecer a importância das Tecnologias de Informação e Comunicação e a urgência de criar conhecimentos e mecanismos que possibilitem sua integração à educação", atendendo às novas demandas educacionais decorrentes do fenômeno da globalização, da transformação da sociedade industrial em sociedade da informação.

Rev. Diálogo Educ., Curitiba, v. 10, n. 29, p. 191-204, jan./abr. 2010 


\section{Breve histórico da EAD}

A Educação a Distância começou no século XV, quando foi inventada a imprensa por Guttenberg na Alemanha. Segundo Alves (2001), a figura do mestre, segundo a história, era desnecessária, além das escolas da época resistirem durante anos ao livro escolar impresso.

Em fins dos anos 70, começa a expansão da metodologia de EAD nos estabelecimentos de ensino no Brasil, especialmente nos grandes centros urbanos, São Paulo e Rio de Janeiro.

As décadas de 80 e 90 supõem um grande avanço, nesse sentido, por causa da introdução das novas tecnologias de informação e comunicação na EAD. Essa inserção permite acesso a um grande número de informações e facilita a comunicação e interação entre os envolvidos no processo de ensino-aprendizagem que, em outra época, eram elementos limitadores.

Atualmente, a Educação a Distância cresce significativamente no Brasil: mais de 1,2 milhão de pessoas estudaram a distância em 2005; das quais, 504.204 estudaram em uma instituição autorizada pelo Sistema de Ensino Brasileiro. Junto a essa proliferação, assistimos também à multiplicação dos tipos de curso (ABRAEAD, p. 2006).

Segundo o mesmo anuário, a Educação a Distância cresce significativamente no Brasil: no ano 2005 foram oferecidos 321 novos cursos, contra 56 novos cursos em 2004. E o número de instituições credenciadas que oferecem educação a distância no Brasil cresceu $30 \%$, o que antes era 166 instituições passou a ser 217.

\section{Indicadores de qualidade para a EAD}

As bases legais da Educação a Distância no Brasil foram estabelecidas pela Lei de Diretrizes e Bases da Educação Nacional Lei n. 9.394/96 (BRASIL, 1996), conhecida por LDB, que foi regulamentada pelo atual Decreto n. 5.622, de 20 de dezembro de 2005 (BRASIL, 2005) e Portaria Ministerial n. 4.361/2004, inclusive para o oferecimento de cursos superiores.

De acordo com Almeida (2008, p. 03):

[...] antes da LDB, com base em artigo referente ao ensino supletivo na Lei no 5692 de 1971, os programa de educação

Rev. Diálogo Educ., Curitiba, v. 10, n. 29, p. 191-204, jan./abr. 2010 
a distância recebiam pareceres dos Conselhos Federal e Estaduais de Educação, eram classificados como 'experimentais', e seu funcionamento permitido a título precário [...] A Portaria 2.253, um dos instrumentos legais que contribuiu para a regulamentação da Educação a Distância no Brasil, provocou grande repercussão no dia-a-dia do sistema educacional universitário [...] Ela trouxe para as Instituições de Ensino Superior (IES) a discussão de como desenvolver, pensar, propor e criar metodologias de ensino que vislumbrem novas maneiras de ensinar e aprender.

Os referenciais de qualidade para a educação superior a distância descrevem dez itens fundamentais que devem ser considerados na preparação dos cursos e programas a distância: compromisso dos gestores; desenho do projeto; equipe profissional multidisciplinar; comunicação/interação entre os agentes; recursos educacionais; infraestrutura de apoio; avaliação contínua e abrangente; convênios e parcerias; transparência nas informações e sustentabilidade financeira.

Devemos lembrar que esses são apenas alguns pontos básicos para garantir qualidade no Ensino Superior a Distância. Entretanto, cada instituição pode acrescentar outros referenciais de acordo com as especificidades próprias do seu contexto.

Destaca-se no referencial de qualidade da Educação a Distância que:

a diferença básica entre educação presencial e a distância está no fato de que, nesta, o aluno constrói o conhecimento - ou seja, aprende - e desenvolve competências, habilidades, atitudes e hábitos relativos ao estudo, à profissão e à sua própria vida, no tempo e local que lhe são adequados, não com a ajuda em tempo integral da aula de um professor, mas com a mediação de professores (orientadores ou tutores) (BRASIL, 2003, p. 03).

Deve-se lembrar que a legislação brasileira reconhece os cursos superiores a distância, da mesma forma que os presenciais, não fazendo distinção entre as modalidades. Para isso, impõe algumas regras de funcionamento aos cursos superiores a distância, dentre elas, podemos destacar: as avaliações, estágio e similares devem obrigatoriamente acontecer de forma presencial e a duração dos cursos a distância deve ser igual à dos cursos presenciais.

Rev. Diálogo Educ., Curitiba, v. 10, n. 29, p. 191-204, jan./abr. 2010 


\section{Modelos de EAD para o ensino superior}

Hoje em dia, assim como existem várias Tecnologias de Informação e Comunicação - TICs, são também diversos os modelos usados para implementação de cursos a distância, pois sua combinação proporciona uma diversidade de opções.

Segundo Moran (2005), há muitas formas de adaptar diferentes pedagogias de acordo com cada aluno e com suas carências. São muitas as possibilidades de escolha: desde um curso a distância, centrado ainda no correio convencional, até um curso totalmente a distância, mediado apenas pelas tecnologias on-line. O leque à disposição é muito amplo.

Nesse item não queremos detalhar todos os modelos de Educação a Distância, nos centramos aqui em dois modelos mais difundidos no Brasil, de cursos que denominamos como: cursos dirigidos a massas e cursos dirigidos a grupos pequenos. A seguir, descrevemos brevemente cada um deles, tentando destacar algumas vantagens e desvantagens.

Os cursos de graduação e de pós-graduação oferecidos a distância estão enquadrados nos modelos de massa e cursos dirigidos a grupos pequenos. Os dois modelos estão baseados na formação de turma, com possibilidade de atividades em grupo, encontros presenciais, formação de comunidades, etc. Esses cursos têm datas previstas para início e término.

Os cursos dirigidos a massas já estão bastante difundidos no Brasil, eles baseiam-se no uso de mídias de massas como ferramenta principal, como por exemplo, aulas televisivas transmitidas via satélite. É um modelo adequado ao aluno que prefere trabalhar junto ao outro no sentido de organizar sua aprendizagem de maneira colaborativa (MORAN, 2005). Os alunos têm de frequentar periodicamente o espaço físico onde acontecem as aulas. Cada sala é monitorada por um tutor local que faz a mediação entre o professor titular e os alunos dos diferentes locais.

Esses cursos se aproximam mais do modelo clássico de ensino, pois os alunos têm o ponto de referência da sala de aula, a qual precisam frequentar com certa assiduidade e manter o vínculo mais estreito com a escola física e com a figura tradicional do professor.

Os cursos dirigidos a grupos pequenos são também cursos com turma, mas têm um diferencial significativo: atendem a uma

Rev. Diálogo Educ., Curitiba, v. 10, n. 29, p. 191-204, jan./abr. 2010 
clientela determinada com o mesmo tipo de necessidades e os alunos não necessitam ir periodicamente à sala de aula. São cursos normalmente mediados pela Internet, nos quais os alunos adquirem maior disciplina, sendo mais independentes na hora de gerenciar seu estudo e sua aprendizagem. Os professores, neste modelo, estão também presentes no processo, entrando em contato com o aluno por meio das ferramentas de comunicação da Internet e via telefone, e, por tratar-se de grupos pequenos, o tratamento dado aos alunos é mais personalizado, tendo condições de acompanhar o desempenho de cada acadêmico mais de perto, tendo uma postura mais de orientador do que transmissor de conhecimento.

É o modelo ideal para pessoas que já estão inseridas no mercado de trabalho, que precisam viajar, têm pouco tempo à disposição, mas querem estudar para conseguir se estabelecer no trabalho ou para ter a possibilidade de ser promovido no emprego. É também o modelo ideal para qualquer pessoa, jovem ou adulto, inserido no mercado de trabalho ou não, que estando motivado para estudar um curso superior, quer exercer sua autonomia no gerenciamento do processo ensino-aprendizagem.

Outra vantagem deste modelo é que oferece maior flexibilidade de tempo e, sobretudo, de espaço. Isso facilita que pessoas que moram no interior (sobretudo em regiões distantes ou de difícil acesso) possam realizar seus estudos de nível superior. Essa flexibilidade está sendo acolhida também por moradores das grandes cidades que preferem evitar os longos deslocamentos e as despesas de locomoção, assim como o desgaste de se submeter diariamente ao estresse dos grandes centros urbanos.

O modelo de cursos dirigidos a grupos pequenos foi o adotado, entre outros Centros de Ensino Superior, pela Universidade Católica Dom Bosco. Com o anseio de oferecer qualidade de ensino a todos: tanto aos que moram nos centros urbanos, mas preferem optar por uma alternativa de estudo mais ousada, arrojada e de qualidade, quanto às pessoas que estariam privadas do acesso ao ensino superior por morarem em localidades distantes dos Centros de Ensino Superior.

Rev. Diálogo Educ., Curitiba, v. 10, n. 29, p. 191-204, jan./abr. 2010 


\section{A inclusão social e a EAD-UCDB}

A proposta pedagógica da UCDB para o desenvolvimento de cursos na educação superior a distância é fundamentada no estímulo ao aprendizado interativo, cooperativo e na autoaprendizagem, para isso, utiliza uma combinação de mídias priorizando a Internet, que promove a autonomia acadêmica de forma responsável e criativa.

Ao longo dos cursos, o aluno deverá estabelecer uma rotina de estudos, mantendo interação constante com o professor, tutor e colegas, para tirar dúvidas, trocar impressões, pedir orientações, partilhar experiências, etc.

Os professores e tutores estão disponíveis para conversas/ esclarecimentos, orientações síncronas ou assíncronas, em horários previamente definidos por meio das ferramentas de comunicação chat, fórum, e-mail e 0800.

Os cursos de Graduação na EAD têm como orientação uma aprendizagem ativa, na qual os acadêmicos estão no centro do processo de ensino-aprendizagem (vide Figura 2). Nesse contexto, a formação de ambiente de cooperação volta-se a uma contínua interação entre os alunos e professores direcionada à formação de uma rede de conhecimentos, integrando as informações novas às já existentes.

O projeto de implantação dos cursos de graduação a distância da UCDB teve como foco principal o oferecimento à população que não tem acesso fácil ao ensino superior, ou por localização ou disponibilidade não flexível de tempo.

Sendo assim, a UCDB iniciou suas atividades nas regiões Norte e Nordeste, onde se percebe claramente a dificuldade de acesso ao ensino superior. Hoje, o modelo de Educação a Distância da UCDB promove a inclusão de alunos que moram no interior de qualquer Estado.

Desde o segundo semestre de 2005, houve três processos seletivos para os cursos de Administração Pública, Administração em Agronegócio e Ciências Contábeis, contabilizando aproximadamente um total de mil alunos matriculados. Conforme pesquisa realizada na última turma de ingressantes no segundo semestre de 2006, 73\% dos alunos da EAD-UCDB moram no interior e apenas $27 \%$ nas capitais de diferentes Estados.

Rev. Diálogo Educ., Curitiba, v. 10, n. 29, p. 191-204, jan./abr. 2010 


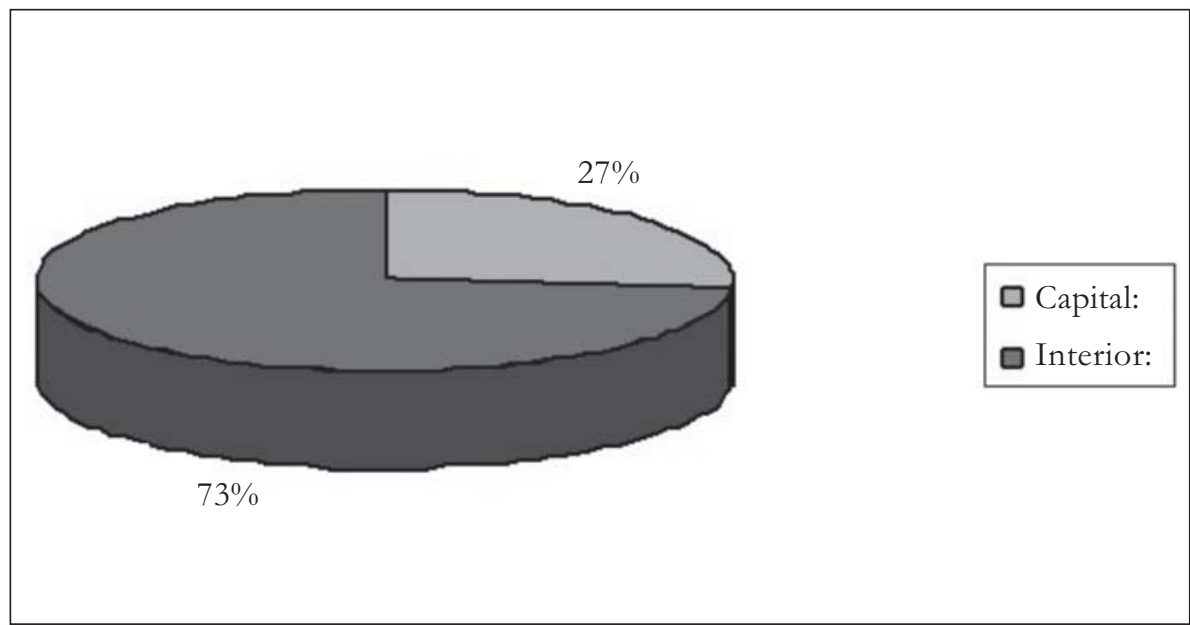

GRÁFICO 1 - Procedência dos alunos

Quanto à idade dos alunos, é interessante destacar que mais da metade tem 35 anos ou mais, indicando que esse modelo é preferido por pessoas adultas, muitas delas já inseridas no mercado de trabalho.

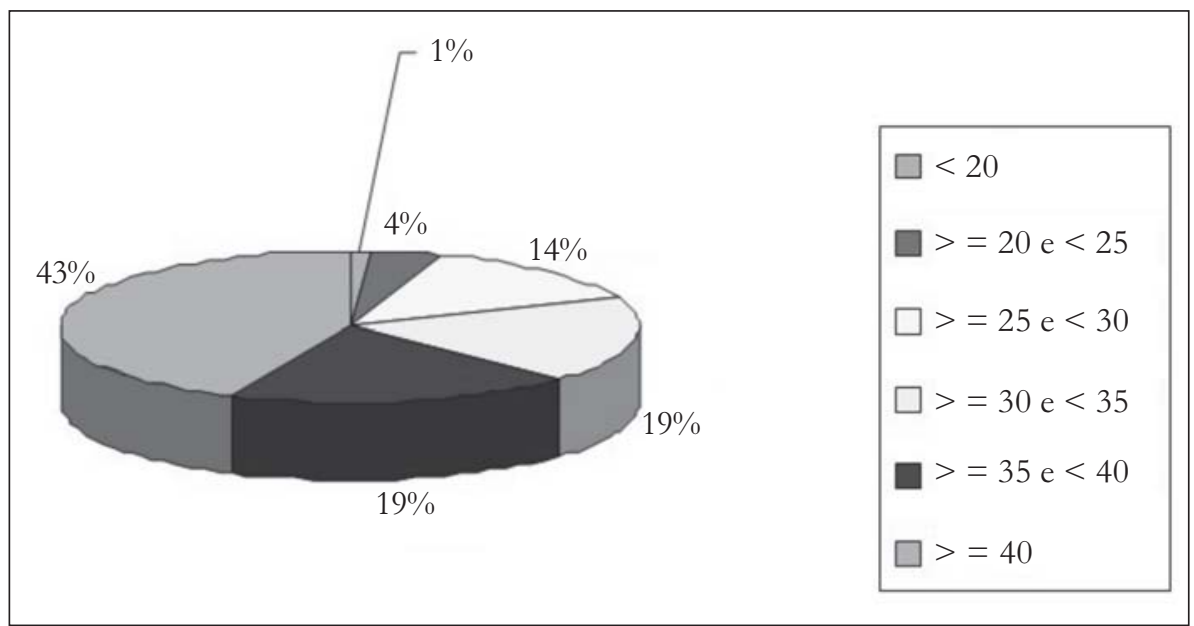

GRÁFICO 2 - Faixa etária dos alunos

Rev. Diálogo Educ., Curitiba, v. 10, n. 29, p. 191-204, jan./abr. 2010 
Por meio de levantamento feito quando do primeiro processo seletivo, verificamos que as justificativas dadas pelos alunos em relação à escolha de um curso de graduação a distância podem ser resumidas nos seguintes aspectos: flexibilidade de tempo e espaço, possibilidade de conciliar trabalho e estudo, necessidade de capacitação, atualização e formação continuada, de acordo com os excertos a seguir (Os excertos são transcritos sem qualquer modificação ou correção):

O fato de estar exercendo a função (de contador) no meu emprego atual está me exigindo mais capacitação.

Por não ter que estar presente todos os dias em uma sala de aula. Dessa forma, não toma muito o meu tempo e não me atrapalha nas minhas atividades do dia-a-dia.

Resido em um local que não possui qualquer faculdade, estando a mais próxima há $150 \mathrm{~km}$ de distância.

É pela facilidade e pela necessidade, pois já exerço a profissão como técnico em contabilidade.

A necessidade profissional, hoje todo bom profissional tem que ser graduado e onde moro não tem uma escola de nivel superior.

Oportunidade de crescerpessoal e profissionalmente, principalmente por morar num município pequeno e de poucas oportunidades.

Com base nesses dados, podemos concluir que cursos oferecidos nesse modelo vêm ao encontro da necessidade concreta de um setor da população de inclusão educacional, pois, caso contrário, estaria impedido de ser um estudante da educação superior. Nesse sentido, de acordo com Mota e Chaves Filho (2005, p. 2):

as demandas por formação continuada ao longo da vida, geradas pelo modo de produção da sociedade do conhecimento, terão na educação a distância forte aliado e, em breve, é possível que não se façam mais distinções entre formação inicial e formação continuada [...] Assim, a prática mediada pelo conjunto das mídias é,per se, conhecimento que coopera ao mesmo tempo com o saber específico e com o incentivo ao aprender a aprender. Constitui-se, ainda, estímulo à aprendizagem continuada.

Rev. Diálogo Educ., Curitiba, v. 10, n. 29, p. 191-204, jan./abr. 2010 
$\mathrm{Na}$ avaliação institucional realizada no primeiro semestre de 2006, pudemos constatar que os alunos estão valorizando positivamente a oportunidade que oferece a EAD-UCDB como refletem os seguintes depoimentos:

Obrigado a vocês da UCDB por tudo que tem feito para a formação de pessoas que sentem a necessidade de alcançar um objetivo que é de uma graduação.

Considero que os conteúdos repassados pelos professores têm me ajudado muito, porque na cidade onde moro não tem uma biblioteca, onde en possa pesquisar.

No men modo de pensar, a realização do curso a distância foi surpreendente e de fácil acesso... é surpreendente já que muitos não podem estar em sala de aula... foi maravilhoso ter este meio de comunicação com pessoas diferentes e estar atendendo nossas expectativas e aprendendo.

$O$ curso que estou fazendo está contribuindo de maneira positiva para o meu trabalho, estou muito satisfeito com tudo o que estou aprendendo, pois apesar de todo dia chegar bastante cansado, procuro reunir forças para estudar... o curso está me proporcionando uma oportunidade de ter uma graduação, pois a EAD tem levado oportunidades para as pessoas que moram no interior do pais, a chance de terem mais conhecimentos, pois hoje tenho o maior orgulho de ser um acadêmico e fazer parte da UCDB.

Esses depoimentos confirmam como a EAD tem colaborado no crescimento humano, social, político, educacional e profissional de seus participantes. Acreditamos que a inclusão social será maior ainda quando houver maior inclusão digital, no sentido de acesso às novas tecnologias e posicionamento crítico diante delas.

\section{CONSIDERAÇÕES FINAIS}

No início, a Educação a Distância era vista como algo totalmente desvinculado da educação presencial. Porém, atualmente estamos assistindo a uma aproximação no sentido de uma contribuição mútua, como destaca Moran (2003, p. 40):

Rev. Diálogo Educ., Curitiba, v. 10, n. 29, p. 191-204, jan./abr. 2010 
A educação online também está começando a trazer contribuições significativas para a educação presencial. Algumas universidades integram aulas presenciais com aulas e atividades virtuais, flexibilizando tempos e espaços e ampliando os espaços de ensino-aprendizagem, até agora praticamente confinados à sala de aula.

Ao invés de ser vista como uma rival, a EAD traz novas possibilidades de comunicação e informação, além de fazer com que repensemos nossas práticas. Portanto, as duas modalidades podem conviver em harmonia, aproveitando o que de melhor cada uma oferece. Podemos prever para o futuro que "estamos caminhando para uma aproximação sem precedentes entre os cursos presenciais e os cursos a distância [...] Teremos inúmeras possibilidades de aprendizagem que combinarão o melhor do presencial (quando possível) com as facilidades do virtual" (MORAN, p. 2005).

Em vista do benefício de inclusão social que a EAD pode propiciar, podemos concordar com Alves ([19—?]), quando afirma que "o custo total (da EAD) é extremamente pequeno se considerarmos que auxilia o resgate da imensa dívida social notada em nosso território".

\section{REFERÊNCIAS}

ANUÁRIO BRASILEIRO ESTATÍSTICO DE EDUCAÇÃO ABERTA E A DISTÂNCIA - ABRAEAD. São Paulo: Instituto Monitor, 2006.

ALMEIDA, O. C. de S. de. Gestão do ensino superior à distância: uma proposta de análise do modelo da Universidade Aberta do Brasil. 2008. Disponível em: <http:/ /www.abed.org.br/congresso2008/tc/55200811205PM.pdf>. Acesso em: 10 jul. 2009.

ALVES, J. R. M. Educação à distância e as novas tecnologias de informação e aprendizagem. 2001. Disponível em: < http://www.engenheiro2001.org.br/ programas/980201a1.htm>. Acesso em: 10 set. 2006.

BELLONI, M. L. Educação à distância. Campinas: Autores Associados, 1999.

BRASIL. Lei n. 9.394, de 20 de dezembro de 1996. Estabelece as diretrizes e bases da educação nacional. Diário Oficial [da] República Federativa do Brasil, Poder Legislativo, Brasília, DF, 23 dez. 1996. p. 27833. Disponível em:

Rev. Diálogo Educ., Curitiba, v. 10, n. 29, p. 191-204, jan./abr. 2010 
$<$ http://www6.senado.gov.br/legislacao/ListaTextoIntegral.action?id=75723>. Acesso em: 23 jul. 2009.

Decreto n. 5.622, de 19 de dezembro de 2005. Estabelece as diretrizes e bases da educação nacional. Diário Oficial [da] República Federativa do Brasil, Poder Executivo, Brasília, DF, 20 dez. 2005. Disponível em: <http:// www.planalto.gov.br/ccivil_03/_Ato2004-2006/2005/Decreto/D5622.htm>. Acesso em: 11 dez. 2008.

Referenciais de qualidade para cursos a distância. 2003. Disponível em: <http://www2.ufscar.br/ead/documentos/referenciaisdeEAD.pdf $>$. Acesso em: 20 jul. 2009.

PERRY, W.; RUMBLE, G. A short guide to distance education. Cambridge: International Extension College, 1987.

HOLMBERG, B. Educación a distancia: situación y perspectivas. Buenos Aires: Kapeluz, 1985.

MORAN, J. M. O que é educação à distância. 1994. Disponível em: <http:/ /www.eca.usp.br/prof/moran/dist.htm>. Acesso em: 2 ago. 2006.

Contribuições para uma pedagogia da educação online. In: SILVA, M. (Org.). Educação online. São Paulo: Loyola, 2003.

Tendências da educação online no Brasil. 2005a. Disponível em: $<$ http://www.eca.usp.br/prof/moran/tendencias.htm>. Acesso em: 10 set. 2006.

MOTA, R.; CHAVES FILHO, H. Educação transformadora e inclusiva. 2005. Disponível em: <http://www.ibict.br/revistainclusaosocial/ viewarticle.php?id=3\&layout $=$ html $>$. Acesso em: 01 set. 2006.

Recebido: $21 / 08 / 2009$

Received: 08/21/2009

Aprovado: 09/10/2009

Approved: 10/09/2009

Rev. Diálogo Educ., Curitiba, v. 10, n. 29, p. 191-204, jan./abr. 2010 